\title{
The incidence of deafness is non-randomly distributed among families segregating for Waardenburg syndrome type 1 (WS1)
}

\author{
Robert Morell, Thomas B Friedman, James H Asher Jr, Leonard G Robbins
}

\begin{abstract}
Waardenburg syndrome (WS) is caused by autosomal dominant mutations, and is characterised by pigmentary anomalies and various defects of neural crest derived tissues. It accounts for over $2 \%$ of congenital deafness. WS shows high variability in expressivity within families and differences in penetrance of clinical traits between families. While mutations in the gene PAX3 seem to be responsible for most, if not all, WS type 1 , it is still not clear what accounts for the reduced penetrance of deafness. Stochastic events during development may be the factors that determine whether a person with a PAX3 mutation will be congenitally deaf or not. Alternatively, genetic background or non-random environmental factors or both may be significant. We compared the likelihoods for deafness in affected subjects from 24 families with reported PAX3 mutations, and in seven of the families originally described by Waardenburg. We found evidence that stochastic variation alone does not explain the differences in penetrances of deafness among WS families. Our analyses suggest that genetic background in combination with certain PAX3 alleles may be important factors in the aetiology of deafness in WS.

(F Med Genet 1997;34:447-452)
\end{abstract}

Keywords: Waardenburg syndrome; WS1; deafness; PAX3

Genetics Program and Department of Zoology, Michigan State University, East Lansing, Michigan 48824-1115, USA R Morell*

T B Friedman $\star$

J H Asher Jr

L G Robbins

$\star$ Present address: Laboratory of Molecular Genetics,

National Institute on

Deafness and Other

Communication Disorders,

National Institutes of Health,

5 Research Court, Rockville,

MD 20850, USA.

Correspondence to: Dr Morell.

Received 6 August 1996 Revised version accepted for publication 10 December 1996 WS1 families with penetrance greater $75 \%$ have also been reported. ${ }^{8-10}$ Estimates for the penetrances of other clinical features of the syndrome are: broad nasal root $(78 \%)$, white forelock (17\%), heterochromia iridum (25\%), and synophrys (45\%).

WS1 maps to chromosome $2 \mathrm{q} 35^{11}$ where mutations in the PAX3 gene have been reported for many type 1 and some type 3 patients. ${ }^{10-20}$ PAX 3 encodes a transcription factor containing two DNA binding motifs: a paired domain and a paired type homeodomain..$^{21}$ It is expressed in developing neural crest cells and in the brain. ${ }^{21}{ }^{22}$ The PAX3 mutations described in WS or WS-like families include amino acid replacements in both DNA binding domains as well as deletions and insertions resulting in frameshifts.

Until recently, linkage analyses suggested that all WS1 mutations cosegregate with PAX3 markers, even in families for which no PAX3 mutation has been identified. ${ }^{11}$ The description of a family in which WS1 is not linked to PAX3 calls this assertion into question, although this family is atypical of WS1 in also having cleft lip and Hirschsprung's disease. ${ }^{23}$

There is no obvious correlation between the nature of the mutations and the resulting phenotypes. ${ }^{11}$ This lack of correlation, coupled with the variability of expression within families, suggests that stochastic events might play a major role in the manifestation of deafness in subjects who are heterozygous for mutant alleles. This hypothesis is supported by observations in the mouse model for WS, Splotch, where the expression of coat colour patches, neural crest cell migration, and spinal ganglion volumes show considerable variability even in highly inbred laboratory strains. ${ }^{24}{ }^{25}$ It is also reasonable to consider the possibility that modifier genes, perhaps under the transcriptional regulation of $\mathrm{PAX} 3$, are responsible for deafness. Surprisingly, the Splotch mouse also provides supporting evidence for this hypothesis, in that Asher et $a l^{26}$ have shown that genes segregating in an interspecific cross modify craniofacial morphology in the presence of a Pax -3 mutation. When comparing the merits of these two hypotheses, it would be useful to know whether the differences in the proportion of deaf people between families is consistent with random fluctuation around a mean proportion, or whether deafness tends to cluster in certain families. Clustering, if it occurs, might be because of the differential effects of either genetic background or environmental factors.

We analysed the variation in penetrances for deafness in 24 published families segregating PAX3 mutations (table 1). We also analysed seven of the 14 families originally described by Waardenburg (table 2). From the set of families described by Waardenburg, ${ }^{1}$ we excluded those 
Table 1 PAX3 mutations and their reported penetrances of deafness. For each mutant allele the type and location of the mutation is listed as well as the numbers of heterozygotes that are deaf and hearing

\begin{tabular}{|c|c|c|c|c|c|}
\hline \multirow[b]{2}{*}{ Family } & \multirow[b]{2}{*}{ Mutation } & \multirow[b]{2}{*}{ Exon } & \multicolumn{2}{|c|}{ Heterozygotes } & \multirow[b]{2}{*}{ References } \\
\hline & & & Deaf & Hearing & \\
\hline WS.055 & F45L & 2 & 3 & 4 & 32 \\
\hline MSU17 & N47L & 2 & 3 & 0 & 3334 \\
\hline BU26 & P50L & 2 & 18 & 5 & 814 \\
\hline BU35 & R56L & 2 & 3 & 0 & 1435 \\
\hline WS.15 & G81A & 2 & 4 & 0 & 920 \\
\hline WS.009 & G99D & 2 & 2 & 1 & 32 \\
\hline MSU3 & 100 ins 1 & 2 & 2 & 0 & 16 \\
\hline WS.05 & 185 del 18 & 2 & 6 & 0 & 919 \\
\hline UGM2 & 266 del 14 & 2 & 8 & 3 & 10 \\
\hline WS.06 & 288 del 1 & 2 & 1 & 6 & 920 \\
\hline BU53 & 297 del 28 & 2 & 3 & 4 & 36 \\
\hline $\begin{array}{l}\text { WS.084 } \\
\text { WS }\end{array}$ & 451 ins 1 & 3 & 1 & 1 & 32 \\
\hline WS.003 & 452 del 2 & 4 & 2 & 1 & 32 \\
\hline WS.11 & 556 del 2 & 4 & 6 & 2 & 920 \\
\hline BU9 & R223X & 5 & 1 & 2 & 36 \\
\hline WS.001 & $\mathrm{Q} 254 \mathrm{X}$ & 5 & 5 & 2 & 937 \\
\hline Hol, 1995 & 598 del 5 & 5 & 1 & 6 & 38 \\
\hline NIH3 & V265F & 6 & 5 & 3 & 15 \\
\hline WS. 10 & $\mathrm{R} 271 \mathrm{C}$ & 6 & 2 & 5 & \\
\hline MSU5 & R271C & 6 & 3 & 8 & 1831 \\
\hline NIH8 & R271G & 6 & 5 & 1 & 15 \\
\hline MSU7 & W274X & 6 & 3 & 1 & \\
\hline MSU9 & 874 ins 1 & 6 & 3 & 0 & 1839 \\
\hline BU25 & 1185 ins 3 & 8 & 8 & 8 & 813 \\
\hline
\end{tabular}

Table 2 Penetrance of deafness among the WS1 families reported by Waardenburg. ${ }^{.}$Families segregating for WS type 2 and those with probable new mutations are excluded. Asterisks indicate that two probands were reported for the family, thus, for likelihood calculations, the penetrance of deafness was corrected assuming a multiple incomplete bias of ascertainment

\begin{tabular}{lll}
\hline \multirow{2}{*}{ Family } & \multicolumn{2}{l}{ Affected subjects $(W S 1)$} \\
\cline { 2 - 3 } & Deaf & Hearing \\
\hline $5^{\star}$ & 4 & 19 \\
$6^{\star}$ & 3 & 1 \\
7 & 1 & 2 \\
9 & 1 & 2 \\
10 & 1 & 15 \\
$11^{\star}$ & 8 & 32 \\
12 & 6 & 5 \\
\hline
\end{tabular}

that were WS2, and those with only a single affected subject born to clinically normal parents. We used the log likelihood ratio test or $G$ test $^{27-29}$ to compare penetrances for deafness among WS families. Our analyses suggest that the aetiology of deafness is dependent on genetic or environmental background or both, and cannot be attributed to stochastic events alone.

\section{Methods}

We reviewed published reports describing PAX3 mutations. Data were included in the analyses only from pedigrees where family relationships and sufficient clinical information were provided in either the mutation report or a previous publication. Only affected people, that is, those shown to be heterozygous for a PAX3 mutation or who had dystopia canthorum in the case of families described by Waardenburg, ${ }^{1}$ were included. A person was classified as either deaf or hearing based upon the published designation. Audiological examination information is not presented in any of the cited references. In the pedigrees described by Waardenburg, ${ }^{1}$ the mutations have neither been characterised nor mapped. The estimation of penetrance in these pedigrees was corrected for ascertainment bias under the assumption of multiple incomplete ascertainment. ${ }^{1}$

Data on the hearing status of affected members were entered into a spreadsheet with each row (i) being a family or a sibship, and each column (j) containing the number of deaf or hearing WS1 people for each row. The $i x j$ table was then smoothed to correct for numerous small and zero cell entries using the method of pseudo-Bayes estimates recommended by Bishop et al. ${ }^{28}$ This accomplishes for a large table what Yates correction does for a $2 \times 2$ table. However, instead of adding an arbitrary amount to each cell, the values are adjusted in a way more commensurate to the variations in size of the cell entries. For each cell $x_{i j}$, total sample size $N$, a weighting factor $k$, and an estimated value of the cell $\lambda_{j}$, the value for each cell in the corrected table is given by:

$$
\chi_{i j}^{*}=\frac{N}{N+k} \chi_{i j} k \lambda_{i j}
$$

where

$$
k=N^{2}-\sum_{i, j} \chi_{i j}^{2} \mid \sum_{i, j}\left(\chi_{i, j}-N \quad \lambda_{i, j}\right)^{2}
$$

For each table, the estimate for $\lambda_{i j}$ used is the expected proportion of affected subjects assuming homogeneity of penetrance in the table, or:

$$
\lambda_{i 1}=\sum i 1 / N \text { and } \lambda_{i 2}=\sum i 2 / N
$$

Thus the entire table was biased towards homogeneity by correcting each cell towards the overall column total $(j=1$ or 2$)$, that is, towards the overall probability of deafness and hearing respectively.

The tables were then used for a series of likelihood ratio tests, tests that are powerful and economical with limited data. For example, to test whether the penetrance for deafness is essentially the same in all families (hypothesis 1 or $\mathrm{H} 1$ ) or whether it is different for each family (H2), we can construct two likelihood functions:

$$
\begin{aligned}
& L(H 1)=\left(P_{N}\right)^{a_{N}}\left(1-P_{N}\right)^{b_{N}} \\
& L(H 2)=\pi_{i=1}^{n}\left(P_{i}\right)^{a_{i}}\left(1-P_{i}\right)^{b_{i}}
\end{aligned}
$$

where for each family $i, a_{i}$ is the number of affected subjects who are deaf, $b_{i}$ is the number of affected subjects with normal hearing, $p_{i}$ is the maximum likelihood estimate for penetrance of deafness in that family, $\mathbf{n}$ is the number of families in the data set, and $N$ refers to the entire pooled data set. For any set of affected subjects, $p_{i}$ is the number of deaf subjects divided by the total number of subjects with the WS1 mutation in a given family. In other words, the ln likelihoods are calculated 
Table 3 Likelihoods of deafness and $G$ tests of hypotheses. In likelihoods were calculated after ascertainment bias correction and pseudo-Bayesian smoothing of the data tables as described in the text

\begin{tabular}{llll}
\hline Hypothesis & $\ln L$ & No of parameters \\
\hline
\end{tabular}

(A) For pedigrees with $P A X 3$ mutations

(A) For pedigrees with $\mathrm{PAX} 3$ mutations
$\mathrm{H} 1$ Penetrance of deafness same for all $\mathrm{PAX} 3$ mutation

$\mathrm{H} 1$ Penetrance of deafness same for all PAX3 mutation

$\mathrm{H} 2$ Penetrance of deafness different for each PAX3 mutation pedigree

H3 Penetrance of deafness different for each sibship of all PAX 3 mutation pedigrees

Comparison
$\mathrm{H} 1 v \mathrm{H} 3$
$\mathrm{H} 1 v \mathrm{H} 2$
$\mathrm{H} 2 v \mathrm{H} 3$

(B) For WS1 pedigrees described by Waardenburg'

H1' Penetrance of deafness same for all Waardenburg pedigrees

H2' Penetrance of deafness different for each Waardenburg pedigree

H3' Penetrance of deafness different for each sibship of all Waardenburg pedigrees

Comparison
$\mathrm{H} 1^{\prime} v \mathrm{H} 3^{\prime}$
$\mathrm{H} 1^{\prime} v \mathrm{H} 2^{\prime}$
$\mathrm{H} 2^{\prime} v \mathrm{H} 3^{\prime}$

(C) Comparison of the two sets

H4 Penetrance same for the two data sets

H5 Penetrance different between the PAX3 mutation and Waardenburg' data sets

$\begin{array}{ll}-109 & 1 \\ -83.8 & 24 \\ -39.9 & 94 \\ G^{2} & p(d f) \\ 196 & <1 \times 10^{-8}(76) \\ 50.5 & 0.0008(23) \\ 87.86 & 0.07(70) \\ -76.1 & 1 \\ -66.7 & 7 \\ -21.0 & 45 \\ G^{2} & p(d f) \\ 110 & <1 \times 10^{-8}(44) \\ 18.8 & 0.004(6) \\ 91.4 & <3 \times 10^{-6}(38) \\ & \\ -216 & 1 \\ -185 & 2 \\ G^{2} & p(d f) \\ 61.8 & <1 \times 10^{-8}(1)\end{array}$

for the summed data and for each row of the spreadsheet.

The $\ln$ likelihoods of the hypotheses were compared by the $\mathrm{G}$ test ${ }^{27}$ using the metric: $\mathrm{G} 2$ $=2 \times(\operatorname{lnL}(\mathrm{H} 1)-\ln \mathrm{L}(\mathrm{H} 2))$.

$\mathrm{G}^{2}$ is distributed approximately as $\chi^{2}$, so the $\mathrm{p}$ value was calculated using the CHIPROB program. ${ }^{30}$ The number of the degrees of freedom is the absolute value of the difference in numbers of parameters estimated in the two hypotheses being compared. ${ }^{28}$ For example, in $\mathrm{H} 1$ one parameter is estimated: the average penetrance of deafness in the entire PAX 3 data set. In $\mathrm{H} 2$ the penetrance in each family is separately estimated, so there are 24 parameters. Thus when comparing $\mathrm{H} 1$ to $\mathrm{H} 2$ there are 23 degrees of freedom. Similarly, in $\mathrm{H} 3$ the penetrance of deafness in each sibship is a separately estimated parameter.

\section{Results and discussion}

The first three columns of table 1 summarise many of the PAX 3 mutations published to date (with references provided in column 6). Reported mutations for which there is insufficient published clinical information or no pedigree structure information are not included in the table. The number of deaf and hearing subjects with PAX 3 mutant alleles are given in columns 4 and 5 . The type of mutation is listed in column 2 , and it is notable that all but one of the reported alleles are unique to each family. The exception is the R271C mutation in WS.10 and MSU5. WS.10 is a British family first reported by Foy et al, ${ }^{9}$ while MSU5 is an American family reported by Asher et al. ${ }^{31}$ These two families do not appear to be related as far as five generations back, but a haplotype analysis has not been done to determine whether the alleles are likely to have the same origin. The penetrance for deafness in the two families is similar: there are two deaf out of seven affected in WS.10 and three deaf out of 11 affected in MSU5. This contrasts with the penetrance for deafness $(5 / 6)$ in NIH8, which segregates for a different missense mutation at the same position (R271G).

Table 2 summarises the hearing status of affected subjects in the seven WS1 families described by Waardenburg. ${ }^{1}$

The question is whether the varying ratios of deaf to hearing among the affected subjects in each family reflects stochastic variation or whether the probability of being deaf differs from family to family. The natural log likelihoods $(\operatorname{lnL})$ for the penetrance of deafness in each family in the PAX3 data set are shown in table 3A. The $\mathrm{G}$ test between $\mathrm{H} 1$ and $\mathrm{H} 2$ gives a value of 50.5. Because 24 parameters are estimated in $\mathrm{H} 2$ (one for each family), and one parameter is estimated in $\mathrm{H} 1$, there are 23 degrees of freedom, resulting in a $\mathrm{p}$ value of 0.0008 .

The heterogeneity among these 24 families indicated by this test could be caused by genetic or environmental effects, but it also could be caused by heterogeneity in ascertainment or in the diagnostic criteria used for "deafness". However, the diagnoses of deafness are probably consistent because all but one of the reports ${ }^{38}$ are from laboratories participating in a consortium with agreed criteria for clinical assignment. ${ }^{40}$

The families described by Waardenburg ${ }^{1}$ have the virtue of being ascertained and diagnosed by a single clinician, with probands identified, thus reducing the potential for heterogeneity resulting from differing ascertainment or diagnostic criteria. The likelihoods for homogeneity among these families (H1') and for heterogeneity (H2') are calculated with ascertainment bias correction and the result of a $G$ test is reported in table 3B. Once again, significant heterogeneity in penetrance among the pedigrees is seen $(p=0.0004)$.

The heterogeneity in both data sets could be ascribed to the effects of unique alleles for each family, differing environmental influences, or differing genetic backgrounds. The influence of these factors needs not be evenly distributed among sibships within pedigrees. Generally, one would expect that the effects caused by a given mutant allele would affect all sibships in a pedigree evenly, environmental factors probably less so, while background genetic factors would be the most specific to sibships because of the unique genetic contributions of the parents who marry into the family. It is logical, then, to evaluate the hypothesis that the penetrance of deafness is different for each sibship (hypotheses designated H3 for the PAX3 data set and H3' for the Waardenburg data set) and compare this with the other hypotheses.

Table 3 summarises the $\operatorname{lnLs}$ for each hypothesis and gives the $\mathrm{G}$ test results of comparisons. Not surprisingly, comparisons of $\mathrm{H} 1$ to $\mathrm{H} 3$ and $\mathrm{H} 1$ ' to $\mathrm{H} 3$ ' yield significant $\mathrm{G}$ statistics, since the heterogeneity already detected among pedigrees is implicit among the sibships of the pedigrees. The more telling comparisons are $\mathrm{H} 2$ to $\mathrm{H} 3$ and $\mathrm{H}_{2}$ ' to $\mathrm{H} 3$ ', which test for heterogeneity of the penetrance of deafness in 
Table 4 Analysis of variation of penetrance with respect to mutation type and location

\begin{tabular}{|c|c|c|c|}
\hline \multicolumn{2}{|c|}{ Hypothesis } & $\ln L$ & No of parameters \\
\hline \multicolumn{4}{|c|}{ (A) Effects of mutation site on penetrance of deafness } \\
\hline Hi & $\begin{array}{l}\text { Penetrance of deafness same regardless of mutation } \\
\text { location by exon }\end{array}$ & -107.8 & 1 \\
\hline \multirow[t]{2}{*}{$\mathrm{H} 2$} & $\begin{array}{l}\text { Penetrance of deafness different depending on exon in } \\
\text { which mutation occurs }\end{array}$ & -104.0 & 6 \\
\hline & $\begin{array}{ll}\text { Comparison } \\
\mathrm{H} 1 v \mathrm{H} 2\end{array}$ & $\begin{array}{l}G^{2} \\
7.62\end{array}$ & $p(d f)$ \\
\hline \multicolumn{4}{|c|}{ (B) Effects of mutation type (missense or nonsenselframeshift) on penetrance of deafness } \\
\hline H1 & Penetrance of deafness same regardless of type & -107.8 & 1 \\
\hline \multirow[t]{3}{*}{$\mathrm{H} 2$} & $\begin{array}{l}\text { Penetrance of deafness different for missense and for } \\
\text { nonsense/frameshift mutations }\end{array}$ & -107.5 & 2 \\
\hline & Comparison & $G^{2}$ & $p(d f)$ \\
\hline & $\mathrm{H} 1 v \mathrm{H} 2$ & 0.6 & $0.44(1)$ \\
\hline
\end{tabular}

sibships over and above the heterogeneity already present among pedigrees. In other words, is there significant clustering of deafness within the sibships of the pedigrees? This would be expected if environmental or genetic background differences contributed to the probability of being deaf, but would not be expected if the nature of the mutant alleles were the major determinant. In the PAX3 mutation data set, no significant evidence for clustering of deaf within sibships was seen $(p=0.07)$, but there was significant evidence in the Waardenburg data set $\left(\mathrm{p}<3 \times 10^{-6}\right)$.

Why is there a significant result for one data set but not the other? Are the data sets essentially the same, or do they represent two different "Waardenburg syndrome populations" with respect to the frequency of deafness? Again, a G test can be performed by writing likelihood statements for the probability of deafness over the two sets. The ln likelihoods for the set comprised of all families pooled together $(\mathrm{H} 4)$ is compared with the sum of lnLs for the PAX3 mutation data set

Table 5 Tests for heterogeneity among pedigrees segregating missense mutations

\begin{tabular}{|c|c|c|c|}
\hline \multicolumn{2}{|c|}{ Hypothesis } & $\ln L$ & No of parameters \\
\hline \multicolumn{4}{|c|}{ (A) Tests for heterogeneity by amino acid replacement, site of replacement, and genetic background } \\
\hline $\mathrm{H} 1$ & Penetrance of deafness same for all amino acid & & \\
\hline & $\begin{array}{l}\text { replacements } \\
\text { Penetrance of deafness different for each amino acid }\end{array}$ & -50.2 & 1 \\
\hline & $\begin{array}{l}\text { replacement (note: data for MSU5 and WS.10 are } \\
\text { combined) }\end{array}$ & -39.4 & 9 \\
\hline H3 & $\begin{array}{l}\text { Penetrance of deafness same among amino acid } \\
\text { replacements in the same DNA binding domain, but } \\
\text { different for the two domains }\end{array}$ & -47.2 & 2 \\
\hline \multirow[t]{8}{*}{$\mathrm{H} 4$} & Penetrance of deafness different for each sibship & -19.5 & 48 \\
\hline & Comparison & $G^{2}$ & $p(d f)$ \\
\hline & $\mathrm{H} 1 v \mathrm{H} 2$ & 21.5 & $0.006(8)$ \\
\hline & $\mathrm{H} 1 v \mathrm{H} 3$ & 6.0 & $0.014(1)$ \\
\hline & $\mathrm{H} 1 v \mathrm{H} 4$ & 62.0 & $0.070(47)$ \\
\hline & $\mathrm{H} 2 v \mathrm{H} 3$ & 15.6 & $0.029(7)$ \\
\hline & $\mathrm{H} 2 v \mathrm{H} 4$ & 39.8 & $0.434(39)$ \\
\hline & $\mathrm{H} 3 v \mathrm{H} 4$ & 55.4 & $0.161(46)$ \\
\hline \multicolumn{4}{|c|}{ (B) Pedigrees segregating amino acid replacements in the paired domain } \\
\hline H1 & Penetrance of deafness same for all alleles & -24.1 & 1 \\
\hline $\mathrm{H} 2$ & Penetrance of deafness different for each allele & -20.1 & 6 \\
\hline \multirow[t]{5}{*}{ H3 } & Penetrance of deafness different in each sibship & -10.6 & 29 \\
\hline & Comparison & $G^{2}$ & $p(d f)$ \\
\hline & $\mathrm{H} 1 v \mathrm{H} 3$ & 27.2 & $0.507(28)$ \\
\hline & $\mathrm{H} 1 v \mathrm{H} 2$ & 8.2 & $0.146(5)$ \\
\hline & $\mathrm{H} 2 v \mathrm{H} 3$ & 19.1 & $0.696(23)$ \\
\hline \multicolumn{4}{|c|}{ (C) Pedigrees segregating amino acid replacements in the homeodomain } \\
\hline $\mathrm{H} 1$ & Penetrance of deafness same for all alleles & -23.5 & 1 \\
\hline $\mathrm{H} 2$ & Penetrance of deafness different for each allele & -20.5 & 3 \\
\hline \multirow[t]{5}{*}{ H3 } & Penetrance of deafness different in each sibship & -11.1 & 19 \\
\hline & Comparison & $G^{2}$ & $p(d f)$ \\
\hline & $\mathrm{H} 1 v \mathrm{H} 3$ & 24.7 & $0.132(18)$ \\
\hline & $\mathrm{H} 1 v \mathrm{H} 2$ & 6.0 & $0.050(2)$ \\
\hline & $\mathrm{H} 2 v \mathrm{H} 3$ & 18.8 & $0.173(14)$ \\
\hline
\end{tabular}

and the Waardenburg data set $(\operatorname{lnL}(\mathrm{H} 1)+$ $\left.\ln L\left(\mathrm{H}^{\prime}\right)=\ln \mathrm{L}(\mathrm{H} 5)\right)$. The results confirm that the two data sets are significantly different (table 3C). This is intuitively obvious when comparing the overall estimates of penetrance for deafness in the two sets. The penetrance of deafness in the PAX3 mutation data set is $61 \%$, and is best estimated as $18 \%$ for the Waardenburg data set (corrected for multiple incomplete ascertainment). It should be noted that the differences in penetrance between the two sets might contribute to a difference in the power of the $G$ test to detect heterogeneity among sibships. Failure to find sibship heterogeneity in the PAX3 set might also be the result of differences in the number of sibships and average size of sibships. A larger number of sibships would result in greater power to detect heterogeneity, but a lower average sibship size would decrease the power of the test. In the PAX3 set there are 77 sibships with average size 1.66; in the Waardenburg set there are 45 sibships with an average size of 2.22 .

Does the penetrance of deafness depend on type and location of mutation in PAX3? Table 4 summarises penetrance of deafness when mutations are categorised by location and then by type. $G$ tests show no significant effects on penetrance of deafness when mutations are categorised by exon location (table 4A). Nor are significant differences observed if the mutations are categorised by type, either as missense or nonsense/frameshift (which includes frameshift mutations and in frame deletions, as well as substitutions creating termination codons) (table 4B). The distinction between missense and nonsense mutations, however, is not always biologically relevant. For example, certain amino acid replacements may be null alleles with regard to binding of the PAX3 protein to particular DNA sequences, such as sequences that regulate a modifier of ear function or development or both. In terms of deafness, these amino acid replacements would be functionally equivalent to mutations that obliterate protein function.

All of the missense mutations are in one of the two DNA binding motifs, the paired domain or the paired type homeodomain (fig 1). A G test of likelihoods for deafness between amino acid replacements in the two domains shows evidence for a significant difference (table 5A, H1 $v$ H3, $\mathrm{p}=0.014$ ). Thus, a missense mutation in the paired domain is more closely correlated with deafness than is a missense mutation in the paired type homeodomain. This difference remains significant even if possible effects of each unique allele are accounted for (table 5A, H2 $v \mathrm{H} 3, \mathrm{p}=0.029$ ). Nor can the heterogeneity be ascribed to the effects of genetic background, since there is no evidence for sibship heterogeneity (table 5A, $\mathrm{H} 2 v \mathrm{H} 4$ and $\mathrm{H} 3 v \mathrm{H} 4$ ). Within each category of missense mutation (that is, either only those families segregating replacements in the paired domain or only those families segregating replacements in the paired type homeodomain) there is also no evidence for sibship heterogeneity (table $5 \mathrm{~B}, \mathrm{C}$ ). There is, however, modest evidence for allelic heterogeneity among the 


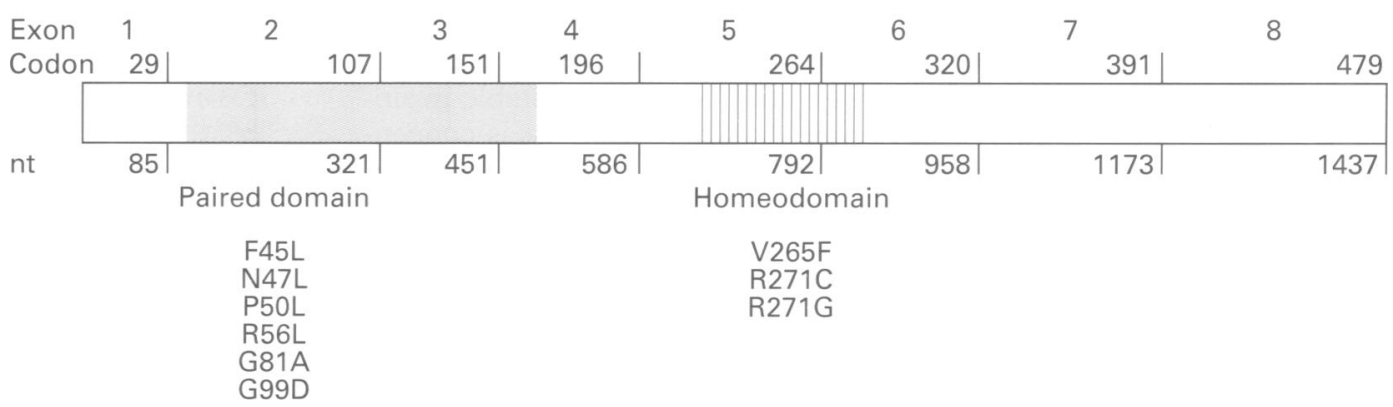

Figure 1 Locations of amino acid replacements in PAX3. Numbers for the 3' most codons and the 3' most nucleotides in each exon are listed at the exon boundaries above and below the ideogram, respectively. Shaded regions indicate the paired domain and the paired type homeodomain. Missense mutations are listed below exons 2 and 6. All amino acid replacements so far described occur in either the paired domain or the paired type homeodomain.

amino acid replacements in the paired type homeodomain (table $5 \mathrm{C}, \mathrm{H} 1 v \mathrm{H} 2, \mathrm{p}=0.05$ ). Thus, neither amino acid replacements in the paired domain nor in the paired type homeodomain show evidence for heterogeneity that could be the result of interactions with the genetic background. However, the two groups of missense mutations are significantly different from each other. When considering this finding, it is useful to bear in mind that alternate transcripts of PAX3, which contain the paired domain but not the paired type homeodomain, have been recovered from adult tissues. ${ }^{41}$ Whether similar transcripts are expressed at critical stages of ear or brain development is unknown. Also, the paired domain and the paired type homeodomain act synergistically to enhance binding to putative consensus sequences, and it is conceivable that both domains may be necessary for proper binding to certain sequences. ${ }^{42-44}$ Finally, it is possible that not all amino acid replacements in the paired type homeodomain are equivalent, with some replacements showing a greater influence of the genetic background on deafness. The evidence for the latter is weak $(\mathrm{p}=0.05)$ given the multiple comparisons performed in these analyses, but cannot be entirely discounted. Until downstream target genes are identified we can only speculate on the functional differences between paired domain and paired type homeodomain missense mutations.

Despite the apparent homogeneity of missense and nonsense/frameshift mutations reported in table 4, tests of heterogeneity among only those pedigrees segregating nonsense/

Table 6 Tests for heterogeneity among pedigrees segregating protein truncating mutations (nonsense substitutions, frameshifts and in frame deletions)

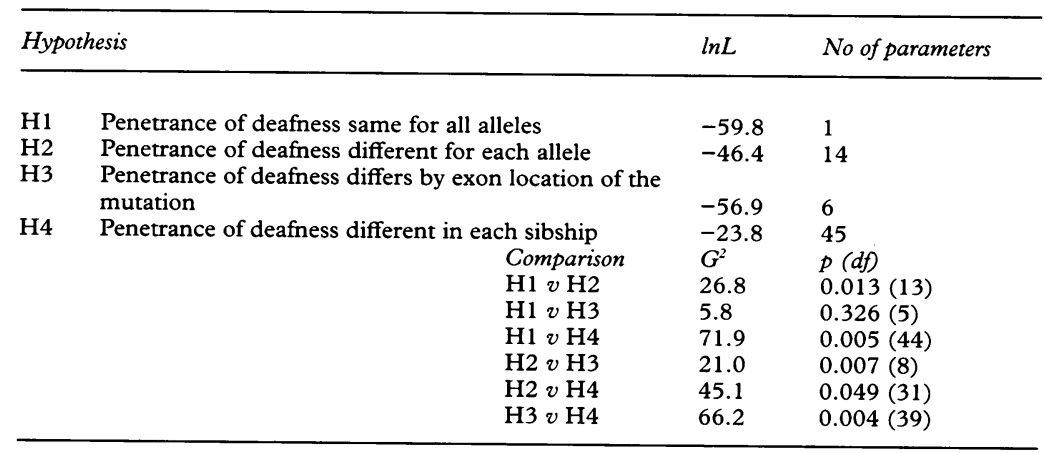

frameshift mutations (table 6) give different results from similar tests performed among pedigrees segregating missense mutations (table 5). Unlike the missense mutations, there is no significant evidence for heterogeneity among the protein truncating mutations when they are classified by the exon location of the mutations (table 6, $\mathrm{H} 1 v \mathrm{H} 3, \mathrm{p}=0.326$ ). There is heterogeneity among the protein truncating mutations, but this can be attributed to differences in genetic background (table 6, $\mathrm{H} 1 v \mathrm{H} 4$, $\mathrm{p}=0.005)$ even when possible allele effects are accounted for (table $6, \mathrm{H} 2 v \mathrm{H} 4, \mathrm{p}=0.049$ ). In the aggregate, the comparisons reported in table 6 indicate that the protein truncating mutations are largely equivalent, and probably obliterate protein function regardless of where the mutation occurs in the gene. The effect that this has on the aetiology of deafness, however, appears to be significantly influenced by parameters that vary from sibship to sibship. As argued earlier, we suggest that this is an influence of genetic background.

Given the high population prevalence of autosomal recessive deafness ${ }^{45}$ the coincidence of carrier status for a recessive deafness gene and heterozygosity for a mutant PAX 3 allele should not be uncommon. If the recessive deafness locus is transcriptionally regulated by PAX3 it would be plausible that haploinsufficiency of PAX 3 could cause deafness in a heterozygote for a mutant recessive deafness allele. This is admittedly speculative, but there is evidence that oligogenic inheritance contributes to WS1 phenotypes, ${ }^{46}$ and that digenic inheritance is involved in the manifestation of the WS type 2 phenotype. ${ }^{48}$ In several families, WS 2 cosegregates with markers both on chromosome 1 and on chromosome $3 .^{49}$ In addition, Asher et $a l^{26}$ have recently shown that the phenotypic expression of a mutant mouse Pax-3 allele is modified, possibly by several genes, in the background introduced in an interspecies cross.

\section{Conclusion}

The present analyses suggest that the aetiology of deafness in Waardenburg syndrome involves the interaction of PAX3 mutations with genetic factors. The evidence we have presented suggests that nonsense mutations are functionally equivalent and that the non-random varia- 
tion arises from genetic background, while missense mutations have an allele specific effect on the aetiology of deafness. It seems probable that attempts to detect loci modifying hearing status would be most profitable in single WS1 families in which deafness is concentrated in sibships. It is also likely that families segregating nonsense rather than missense mutations would be more informative. Such analyses would benefit from a comprehensive audiological evaluation in all subjects, including the unaffected parents, who might have subclinical hearing impairments indicative of carrier status for recessive deafness genes. While the identification of modifier genes influencing the penetrance of deafness in WS1 families may be difficult, it should be reassuring to know that they exist and that the variability of deafness in WS1 is not a wholly stochastic event.

This work was supported in part by research grant number R01 DC01160 from the National Institute on Deafness and othe Communication Disorders, National Institutes of Health (to JHA and TBF) and by grant MCB-9305846 from the Nationa Science Foundation (to LGR). JHA died during completion of this paper.

1 Waardenburg PJ. A new syndrome combining developmen tal anomalies of the eyelids, eyebrows and nose root with pigmentary defects of the iris and head hair with congenital deafness. Am F Hum Genet 1951;3:195-253.

2 Mendelian inheritance in man - online database (program). Baltimore: Johns Hopkins University Press, 1996.

3 Partington MW. Waardenburg's syndrome and heterochromia iridum in a deaf school population. Can Med Ass 1964;90:1008-17.

4 Hageman MJ, Delleman JW. Heterogeneity in Waardenburg syndrome. Am $\mathcal{f}$ Hum Genet 1977;29:468-85.

5 Bard LA. Heterogeneity in Waardenburg's syndrome. Arch Ophthalmol 1978;96:1193-8.

6 Arias S. Genetic heterogeneity in the Waardenburg Arias S. Genetic heterogeneity in the
syndrome. Birth Defects $1971 ;$ VII (4):87-101.

7 Liu XZ, Newton VE, Read AP. Waardenburg syndrome type II: phenotypic findings and diagnostic criteria. $A m \mathcal{F}$ Med Genet 1994;53:1-8.

8 da-Silva EO. Waardenburg I syndrome: a clinical and genetic study of two large Brazilian kindreds, and literatur review. Am $\mathcal{f}$ Med Genet 1991;40:65-71.

9 Foy C, Newton V, Wellesley D, Harris R, Read AP. Assignment of the locus for Waardenburg syndrome type I to human chromosome 2q37 and possible homology to the splotch mouse. Am $\mathcal{F}$ Hum Genet 1990;46:1017-23

10 Morell R, Friedman TB, Moeljopawiro S, Hartono Soewito, Asher JH Jr. A frameshift mutation in the paired domain of HuP2 is responsible for Waardenburg syndrom type 1 in an Indonesian family. Hum Mol Genet 1992;1: 243-7.

11 Farrer LA, Arnos KS, Asher JH Jr, et al. Locus heterogeneity for Waardenburg syndrome is predictive of clinical subtypes. Am f Hum Genet 1994;55:728-37.

12 Baldwin CT, Hoth CF, Amos JA, da Silva EO, Milunsky A An exonic mutation in the $\mathrm{HuP2}$ paired domain gene An exonic mutation in the HuP2 paired domain gene

13 Baldwin CT, Hoth CF, Macina RA, Milunsky A. Mutations in PAX 3 that cause Waardenburg syndrome type I: ten new mutations and revi

14 Hoth CF, Milunsky A, Lipsky N, Sheffer R, Clarren SK, Baldwin CT. Mutations in the paired domain of the human PAX3 gene cause Klein-Waardenburg syndrome (WSIII) as well as Waardenburg syndrome type I (WSI). Am F Hum Genet 1993;52:455-62.

15 Lalwani AK, Brister JR, Fex J, et al. Further elucidation of the genomic structure of PAX3, and identification of two different point mutations within the PAX 3 homeobox that cause Waardenburg syndrome type 1 in two families. $A m \mathcal{F}$ Hum Genet 1995;56:75-83.

16 Morell R, Friedman TB, Asher JH Jr. A plus-one frameshift mutation in PAX3 alters the entire deduced amino acid sequence of the paired box in a Waardenburg syndrome type 1 (WS1) family. Hum Mol Genet 1993;2:1487-8.

17 Morell R. Mutations responsible for Waardenburg syndromes type 1 and 2. PhD dissertation, Michigan State University, type 1 an.
1993.

18 Morell R, Carey ML, Lalwani AK, Friedman TB, Asher JH Jr. Three mutations in the paired homeo domain of $P A X 3$ that cause Waardenburg syndrome type 1. Hum Hered (in press).

19 Tassabehii M, Read AP, Newton VE, et al. Waardenburg's syndrome patients have mutations in the human homosyndrome patients have mutations in the human homo-
20 Tassabehii M, Read AP, Newton VE, et al. Mutations in the PAX3 gene causing Waardenburg syndrome type 1 and type 2. Nat Genet 1993;3:26-30.

21 Goulding MD, Chalepakis G, Deutsch U, Erselius JR, Gruss P. Pax-3, a novel murine DNA binding protein expressed during early neurogenesis. $E M B O \mathcal{F}_{1991 ; 10 \text { : }}$ 1135-47.

22 Stuart ET, Kioussi C, Gruss P. Mammalian PAX genes. In: Campbell A, Anderson W, Jones E, eds. Annual review of genetics. Palo Alto: Annual Reviews Inc, 1994:219-36.

23 Pierpont JW, St Jacques D, Seaver LH, Erickson RP. A family with unusual Waardenburg syndrome type I (WSI), cleft lip (palate), and Hirschsprung disease is not linked to PAX3. Clin Genet 1995;47:139-43.

24 Moase CE, Trasler DG. Spinal ganglia reduction in the splotch-delayed mouse neural tube defect mutant. Teratology 1989;40:67-75.

25 Moase CE, Trasler DG. Delayed neural crest cell emigration from $\mathrm{Sp}$ and $\mathrm{Spd}$ mouse neural tube explants. Teratology 1990;42:171-82.

26 Asher JH Jr, Harrison RW, Morell R, Carey ML, Friedman TB. Effects of Pax 3 modifier genes on craniofacial morphology, pigmentation, and viability: a murine model of Waardenburg syndrome variation. Genomics 1996;34: 285-98.

27 Woolf B. The log-likelihood ratio test (the G-test). Ann Hum Genet 1957;21:397-409.

28 Bishop YMM, Fienberg SE, Holland PW. Discrete multivariate analysis: theory and practice. Cambridge, MA: MIT Press, 1975.

29 Edwards AWF. Likelihood. Baltimore: Johns Hopkins University Press, 1992.

30 Terwilliger JD, Ott J. Handbook of human genetic linkage. Baltimore: Johns Hopkins University Press, 1994.

31 Asher JH Jr, Morell R, Friedman TB. Waardenburg syndrome (WS): the analysis of a single family with a WS 1 mutation showing linkage to RFLP markers on human chromosome 2q. Am $\mathcal{f}$ Hum Genet 1991;48:43-52.

32 Tassabehji M, Newton VE, Read AP. Waardenburg syndrome type 2 caused by mutations in the human microphthalmia (MITF) gene. Nat Genet 1994;8:251-5.

33 Asher JH Jr, Sommer A, Morell R, Friedman TB. Missense mutation in the paired domain of $P A X 3$ causes mutation in the paired domain of PAX3 causes craniof

34 Sommer A, Young-Wee T, Frye T. Previously undescribed syndrome of craniofacial, hand anomalies and sensorineural deafness. Am $\mathcal{F}$ Med Genet 1983;15:71-7.

35 Carezani-Gavin M, Clarren SK, Steege T. Waardenburg syndrome associated with meningomyelocele. $A m \mathcal{F} \mathrm{Med}$ Genet 1992;42:135-6.

36 Baldwin CT, Lipsky NR, Hoth CF, Cohen T, Mamuya W, Milunsky A. Mutations in PAX 3 associated with Waardenburg syndrome type I. Hum Mutat 1994;3:205-11.

37 Tassabehij M, Newton VE, Liu XZ, et al. The mutational spectrum in Waardenburg syndrome. Hum Mol Genet 1995;4:2131-7.

38 Hol FA, Hamel BCJ, Geurds MPA, et al. A frameshift mutation in the gene for PAX 3 in a girl with spina bifida and mild signs of Waardenburg syndrome. $f$ Med Genet 1995;32:52-6.

39 Kapur S, Karam S. Germ-line mosaicism in Waardenburg syndrome. Clin Genet 1991;39:194-8.

40 Farrer LA, Grundfast KM, Amos J, et al. Waardenburg syndrome (WS) type 1 is caused by defects at multiple loci, one of which is near ALPP on chromosome 2: first report of the WS consortium. Am F Hum Genet 1992;50:902-13.

41 Tsukamoto K, Nakamura Y, Niikawa N. Isolation of two isoforms of the PAX 3 gene transcripts and their tissueisoforms of the PAX 3 gene transcripts and their tic alternative expression in human adult tissues. Hum specific alternative exp

42 Wilson D, Sheng G, Lecuit T, Dostatni N, Desplan C. Cooperative dimerization of paired class homeo domain Cooperative dimerization of paired clas

43 Underhill DA, Vogan KJ, Gros P. Analysis of the mouse Splotch-delayed mutation indicates that the Pax-3 paired domain can influence homeodomain DNA-binding activity. Proc Natl Acad Sci USA 1995;92:3692-6.

44 Chalepakis G, Jones FS, Edelman G, Gruss P. Pax-3 contains domains for transcription activation and transcription inhibition. Proc Natl Acad Sci USA 1994;91 $12745-9$.

45 Cohen MMJ, Gorlin RJ. Epidemiology, etiology, and genetic patterns. In: Gorlin RJ, Toriello HV, Cohen MMJ, ed pereditary hearing loss and its syndromes. Oxford: Oxford Hereditary hearing loss and
University Press, 1995:9-21.

46 Pandya A, Xia XJ, Landa BL, et al. Phenotypic variation in Pandya A, Xia XJ, Landa BL, et al. Phenotypic variation in Waardenburg syndrome: mutational heterogeneity, modi5:497-502.

47 Morell R, Pierpont J, Guo W, et al. A frameshift mutation in MITF co-segregates only with Waardenburg syndrome type 2 (WS2) in a family with both WS2 and ocula albinism (OA) (abstract 1276). Am f Hum Genet 1995;54: A221

48 Morell R, Spritz RA, Ho L, et al. Apparent digenic inheritance of Waardenburg syndrome type 2 (WS2) an autosomal recessive ocular albinism (AROA). Hum Mol Genet (submitted)

49 Lalwani AK, Baldwin CT, Morell R, et al. A locus for Waardenburg syndrome type II maps to chromosom 1p13.3-2.1. Am F Hum Genet 1994;55:A14. 